This is the pre-peer-reviewed version of the following article 'Intuitional Disagreement', The Southern Journal of Philosophy Volume 50, Issue 4, December 2012, 639-659, which has been published in final form at http://onlinelibrary.wiley.com/doi/10.1111/j.2041-

6962.2012.00139.x/abstract.

\title{
Intuitional Disagreement
}

\author{
Folke Tersman \\ Uppsala University
}

\section{Introduction}

So-called 'experimentalists' argue that recent empirical research has revealed facts that undermine the reasonableness of appealing to intuitions in the way philosophers do. ${ }^{1}$ These worries are in turn supposed to support a more general skepticism about what traditional philosophical theorizing can achieve, given the crucial role intuitions play in philosophical argumentation. For example, Stephen Stich writes:

For 2500 years, philosophers have been relying on appeals to intuition. But the plausibility of this entire tradition rests on an unsubstantiated, and until recently unacknowledged, empirical hypothesis - the hypothesis that the philosophical intuitions of people in different cultural groups do not disagree. Those philosophers who rely on intuition are betting that the hypothesis is true. If they lose their bet, and if I am right that the prospects are very dim indeed for producing a convincing theory of error, which explains why a substantial part of the world's population has false intuitions about knowledge, justice, happiness and the like, then a great deal of what goes on in

\footnotetext{
${ }^{1}$ For some of the relevant results, see Nichols, S., Stich, S., and Weinberg, J., 'Metaskepticism: Meditations in Ethno-Epistemology', in Luper S., (ed.), The Skeptics, Burlington, VT: Ashgate, 2003, Nichols, S., and Ulatowski, J., 'Intuitions and Individual Differences: The Knobe Effect Revisited'. Mind \& Language 22, 2007, 346-365, Swain, S., Stich, S., 'Reflective Equilibrium, Analytic Epistemology and the Problem of Cognitive Diversity', in DePaul, M. and Ramsey, W. (eds.), Rethinking Intuition: The Psychology of Intuition and its Role in Philosophical Inquiry, Rowman and Littlefield, 1998, 95-112, Swain, S., Alexander, J. and Weinberg, J., 'The instability of philosophical intuitions: Running hot and cold on Truetemp'. Philosophy and Phenomenological Research 76, 2008, 138-155, Weinberg, J., 'How To Challenge Intuitions Empirically Without Risking Skepticism', Midwest Studies in Philosophy: Philosophy \& the Empirical 31, 2007, 318-343.
} 
contemporary philosophy, and a great deal of what has gone one in the past, belongs in the rubbish bin. ${ }^{2}$

As the quote illustrates, one reason why the findings are taken to generate skeptical conclusions is that they suggest that peoples' intuitions vary extensively, depending on cultural background, class and other factors. These patterns of variation are held to be hard to reconcile with the assumption that the intuitions are even moderately reliable, which in turn should make us weary, it is held, also about the further claims that are based on them.

The plausibility of drawing skeptical conclusions from the existence of intuitional disagreement is usually taken to be conditional on a realist understanding of the area in which the contested intuitions are employed. Such a view entails that the issues addressed in the area allow for true or false answers whose truth or falsity is independent of us in relevant ways. A possible response to the existence of disagreement is therefore to reject realism and to adopt some form of anti-realism, such as expressivism or relativism. For example, Stich takes the (alleged) fact that Westerners are disposed to apply concepts such as 'justice' differently from East Asian to lead to skepticism on the ground that some of the differing verdicts must be false, given that they are logically incompatible. However, there are versions of relativism that allow us to resist that conclusion. The versions I am thinking of imply that sentences such as, say, ' $\mathrm{X}$ is just' have different truth conditions for different speakers, depending on the cultural group to which the speakers belong. Obviously, if a sentence has different truth conditions for two speakers, they need not have genuinely conflicting beliefs just because they give different verdicts on it. Thus, none of them need to be in error. ${ }^{3}$

If one adopts relativism on the ground that it allows one to avoid skepticism, then one presupposes that the fact that a position leads to skepticism is a reason to reject it. The plausibility of this presupposition is not obvious. However, in what follows, I shall ignore that issue. ${ }^{4}$ Instead, I shall focus on the question of if intuitional disagreement really does provide skeptical worries, even assuming a realist view. I shall first reconstruct the experimentalists' challenge and then examine one increasingly popular strategy for responding to it. From now

2 'Replies', in Murphy, D., (ed.), Stich and his critics, Melden, MA: Blackwell, 2009, 190-252.

3 Examples of this type of relativism are developed in Harman, G., 'Moral Relativism Defended', Philosophical Review 84, 1975, 3-22.Wong, D. Moral Relativity. Berkeley: University of California Press, 1984.

${ }^{4}$ I explore that question in my Moral Disagreement, New York: Cambridge University Press, 2006. 
on, I shall concentrate on ethics and on moral intuitions, although much of the subsequent discussion applies, I think, equally well to other philosophical areas. 5

The response in question differs from others in that it invokes substantive moral assumptions; i.e., assumptions of the very kind the challenged intuitions are used to support. This may seem as a non-starter, since invoking such assumptions in defense of the intuitions might appear circular in a problematic way. However, an underlying idea, to which I shall return, is that no potential source of evidence, including observation, can be justified in an entirely non-circular way. Any available defense of the reliability of observations will also have to invoke assumptions whose plausibility can only be established with reference to judgments of the challenged type (i.e., observations). This is relevant, since the type of skeptical conclusion I shall discuss, and that is sought by Stich et al, is a local one. They tend to concede that their challenge fails if it collapses into global skepticism.

In other words, the question is if intuitional disagreement gives us any reason to be more humble about the justification of the claims and theories that are advanced in ethics than regarding the theories that are put forward in other disciplines, such as, for example, the sciences. Obviously, if no alleged source of evidence can be given a non-circular justification, then the absence of such a justification in the case of the evidence ethicists appeal to doesn't support the type of mixed verdict that Stich and other skeptics seek. However, although I think the strategy that invokes substantive moral assumption is in fact the one that holds most promise, I shall argue that the prospects are ultimately bleak. In a nutshell, the point I shall make is this: The problem with the strategy is not that it is circular, but rather that the moral claims it requires are not confirmed by the intuitions whose reliability it may help to establish. This marks a contrast with the observational case, where the relevant assumptions are confirmed by the target judgments.

The plan of the paper is as follows. The primary target of the experimentalists' challenge is the idea that intuitions deserve being treated as evidence in the sense that they provide considerations that might justify belief in the truth of a philosophical theory. In sections 2 and 3, I clarify that idea and explain why its alleged implausibility is supposed to have wider skeptical implications for philosophy. The response to the challenge that provides the focus of my paper is motivated by the idea that a non-skeptic must provide a believable positive defense of the reliance on intuitions. In section 4 , I defend that idea. In sections 5 and 6 , the

\footnotetext{
${ }^{5}$ Since I want to explore if intuitional disagreement generates skeptical conclusions given a realist view, I thus assume that such a view applies to ethics (i.e., that moral convictions can be (independently) true).
} 
response-which consists of suggestions about how to provide such a defense-is reconstructed. In section 7, I state a number of conditions a defense along the pertinent lines must satisfy, and, in section $8, \mathrm{I}$ argue that it is unlikely that any such defense satisfies those conditions. In section 9, finally, some concluding remarks are made.

\section{The target of the challenge}

There is a distinction that, in spite of its familiarity, continues to cause confusion in the debate about the epistemic status of intuitions. Sometimes, when philosophers talk of intuitions they simply refer to certain propositions, such as the claim that it would be right, in the famous trolley case, to reroute the trolley by flipping the switch (so that it kills one instead of five persons). ${ }^{6}$ On other occasions, however, the term 'intuitions' rather refer to instances of the psychological attitude we have towards a proposition when 'intuiting' that it is correct or plausible. In other words, we should distinguish between the 'having' of an intuition and its content, and the confusion stems from the fact that when people affirm or deny that intuitions can be evidence, it is not always clear to what they refer.

There is some controversy about the nature of the relevant attitude. A typical example of an intuition is a verdict on a real or hypothetical scenario that the subject forms simply by reflecting on the case and prior to consciously applying any theory. In particular, it is assumed that the attitude must not be the result of an inference from the theory we want to test against the intuition. But there is disagreement about whether it is a belief, a disposition to hold a belief, or something different from a belief altogether; something with its own distinctive phenomenology. For example, some view intuitions as a type of intellectual 'seemings' and make a (partial) analogy with perceptual seemings. ${ }^{7}$ These differences will not have any importance in what follows, however, so I shall ignore them. ${ }^{8}$

As for the propositions that are classified as intuitions (on the ground that they are the objects of the relevant attitude), some of them, such as the trolley-intuition, concern particular

\footnotetext{
${ }^{6}$ For an early account of the trolley case, see Thomson, J., 'Killing, Letting Die, and the Trolley Problem', The Monist 59, 1967, 204-217.

${ }^{7}$ See, e.g., Huemer, M., Ethical Intuitionism, Palgrave Macmillan, 2006. An example of a perceptual seeming is the appearance that the lines are of different length in the Müller-Lyer illusion. One similarity is held to be that one can have the relevant seeming without having the corresponding belief (since one knows that the appearance is misleading).

${ }^{8}$ But note that they do have different implications regarding issues that may be relevant, such as the extent of intuitional disagreement that exists. Thus, many who ultimately reject the view that we should flip the switch in the initial trolley case still have the inclination to hold the opposite view. So, given the view that intuition does not entail belief, the existing intuitional disagreement may be less.
} 
cases. However, more general and abstract claims verdicts are also in some cases held to be the objects of intuitions. An example is the thesis that 'betterness' is a transitive relation; i.e., that if $\mathrm{A}$ is better than $\mathrm{B}$ and if $\mathrm{B}$ is better than $\mathrm{C}$, then $\mathrm{A}$ is also better than $\mathrm{C}$. I shall go along with this tolerant view about what the content of an intuition could be.

The tendency to draw wider skeptical conclusions from the doubts about intuitions is based on the assumption that they actually do play an essential role in philosophical argumentation. This is an assumption that has been criticized, for example by Tim Williamson. In assessing Williamson's criticism, it is important to keep the distinction between the having of an intuition and its content in mind.

The having of an intuition is a psychological entity. What Williamson denies is that it is such items that play the role of evidence in philosophy. He concedes that they provide evidence for some of the claims philosophers make, namely linguistic and conceptual claims. Thus, when we hesitate to apply the term 'knowledge' in a Gettier scenario this presumably says something about the meaning of the term in our idiolect. But he stresses that most philosophical theories do not make claims of that kind. They do not concern our concepts but, as he puts it, 'the extra-mental and extra-linguistic' aspects of reality. Epistemologists study knowledge-what knowledge is-and not just our concept of knowledge. Ethicists study rightness - what makes actions right—and not the meaning of the word 'right'.

If the claims philosophers make concern the extra-mental and extra-linguistic aspects of reality, it is indeed hard to see how psychological entities of the type the having of an intuition exemplifies can be directly relevant. What, then, is their evidence? According to Williamson, the evidence consists in true propositions, but not in propositions about us but about the subject matters that the theories and claims they consider are about. That is, it consists of propositions that can form the objects of intuitions, such as the claim that it would be right, in the trolley case, to flip the switch. ${ }^{10}$

This, however, is a point those who stress the role of intuitions obviously can acknowledge. That is, they can acknowledge that it is the propositions that constitute the contents of our intuitions that philosophical theories are tested against rather than the having

\footnotetext{
${ }^{9}$ See Williamson's The Philosophy of Philosophy, Oxford: Blackwell, 2008, 264. For a similar view about the content of philosophical claims, see Kornblith, H., 'Naturalism and Intuitions', Grazer Philosophische Studien 74, 2007. 27-49 and Sosa, E., 'Experimental Philosophy and Philosophical Intuition', Philosophical Studies 132, 99-107, esp. 100. In my view, the distinction between conceptual and other claims is less clear than what Williamson assumes. But I shall nonetheless go along with his way of seeing things.

${ }^{10}$ See Tersman. F., 'The Reliability of Moral Intuitions: A Challenge from Neuroscience', Australasian Journal of Philosophy86, 2008, 389-405, for further discussion.
} 
of those intuitions. They are tested against those propositions in the sense that, if they conflict with them, that is seen to be a (defeasible) reason to reject them, while, if they can accommodate and even explain them, that is seen to be a (defeasible) reason to accept them. The appeal to the psychological aspect of intuitions plays a different role. It pertains rather to the question of why the propositions in question deserve being treated with that respect.

The primary target of the skeptics' challenge is a particular answer to that question, namely the thesis that the propositions deserve being treated as evidence because they are the objects of intuitions. More specifically, according to the answer in question, if we intuit that $\mathrm{P}$, then, in some cases at least, this indicates or is evidence that $\mathrm{P}$, which is why we have a reason to reject theories that imply not-P. I shall call that answer 'the reliability of intuitions thesis' or RIT.

An analogy is here sometimes made with observations and perceptual beliefs. ${ }^{11}$ The term 'observation' is ambiguous in the same way as 'intuition'. It could refer to the content of the attitude we have when observing something or to an instance of that attitude itself. Obviously, it is against the contents of our observations that scientific theories are tested, but it is the fact that they are the objects of the attitude that justifies giving them that role.

It is easy to see how the results to which Stich et al appeal creates a prima facie challenge for RIT. For example, some studies suggest that people's intuitions are influenced by the order in which they ponder the cases their intuitions concern and by features of the environment in which they consider the cases (whether they sit at a messy desk or a tidy one, and so on). These factors clearly vary independently of the correctness of the intuitions. Thus, given their influence, relying on a set of propositions on the ground that they are intuitively held would seem to be like judging what the time is on the basis of the readings of a thermometer. Moreover, the fact that people's intuitions diverge poses of course in itself a potential threat to RIT. In support of RIT, one may argue that intuitions are reliably formed in the sense that they are the result of a process that generally leads to true judgments. Extensive disagreement is hard to reconcile with the assumption that all those intuitions are reliably formed, even if we don't suppose that a reliable process must be foolproof.

\section{The relevance of $R I T$}

The response to the skeptics' challenge that I shall explore tries to reconcile the supposedly troubling empirical facts with (a qualified version of) RIT. However, another option is to deny

\footnotetext{
${ }^{11}$ See, e.g., Sosa, 'Experimental Philosophy and Philosophical Intuition', 105.
} 
that RIT is relevant in the way the skeptics think it is. Why is the alleged implausibility of RIT supposed to lead to a wider skepticism about philosophical knowledge claims?

In support of the view that it does, two considerations are commonly adduced. First, note that the falsity of RIT merely rules out one possible way of arguing that the intuitions philosophers offer as evidence deserve being treated as evidence, namely that which appeals to the fact that they are intuitively held. This does not exclude that there are other ways. However, if a non-skeptic insists that there is such an alternative defense then she must presumably explain what it is. One option is to defend the target propositions by appealing to yet further propositions, from which the target ones could somehow be derived. The problem is that this threatens to lead to a regress. Second, the challenge aims to establish that there is contrast, in terms of justification, between ethical knowledge claims and those that are made, for example, in the sciences. To use a term due to Alvin Goldman, if the fact that we have a certain attitude towards a proposition $\mathrm{P}$ indicates or is evidence that $\mathrm{P}$ is true, then the attitude is a 'basic evidential state'. ${ }^{12}$ Scientific knowledge claims obtain support from such states, since they are supported by observations. However, if no moral intuition is a basic evidential state, as the falsity of RIT entails, ethical knowledge claims do not. This is enough, it is held, to establish that there is the contrast skeptics think exists.

There are several objections to the above arguments. For example, one may point out that the alleged fact that no moral intuition is a basic evidential state does not exclude that ethical claims can be justified with reference to other states of that kind (i.e., non-moral judgments), such as observations. However, even disregarding the potentially undermining implications in this context of the is-ought divide, I think it is fair to say that observations have a very limited role when it comes to adjudicating between the ethical theories that dominate the contemporary debate. ${ }^{13}$ I'm not going to pursue this discussion, however, as I shall focus on the plausibility of RIT rather than its significance. In other words, in what follows, I shall assume that RIT is relevant in the way assumed by the skeptical challenge I am focusing on.

\footnotetext{
${ }^{12}$ Goldman, A., and Pust, J., 'Philosophical theory and intuitional psycho-evidence', in DePaul, M and Ramsey, W., (eds.), Rethinking Intuition: The Psychology of Intuition and its Role in Philosophical Inquiry, Maryland: Rowman and Littlefield, 1998, 179-200.

${ }^{13}$ Another objection to the arguments for the relevance of RIT seem to presuppose some version of epistemic foundationalism, as the underlying idea appears to be that skepticism can be avoided only if some beliefs are non-inferentially justified. This may in turn appear problematic, as there are competing views, such as coherentism (note that the method that is most commonly associated with the use of intuitions - the idea of reflective equilibrium - is a version of that theory). However, the argument does not in fact exclude coherentism, as I try to explain in my Reflective Equilibrium, Stockholm: Almqvist \& Wiksell, 1993, chapter 6.
} 


\section{Restricting RIT}

In trying to reconcile the potentially undermining empirical results about intuitions with RIT, many non-skeptics stress their inconclusiveness. Some of the studies face methodological problems, and the number of researched subjects is often quite limited. They usually consist of a few students who have little training in pondering thought experiments and who don't comprise a representative sample of the general community of 'intuiters'. Moreover, although some of the claims that are the objects of our moral intuitions are contested, others are not, such as the thesis about the transitivity of betterness mentioned earlier, or the view that it is wrong to torture babies for fun. ${ }^{14}$ So, given the data that has so far been gathered, some intuitions, or some peoples' intuitions, seem untouched by the worries. A non-skeptic can accordingly respond to the challenge by restricting her claim about the reliability of our intuitions to those that are thus untouched, such as those that are more or less universally shared, in the hope that they provide a sufficient basis for further claims.

This may seem as a promising strategy, but there are problems. To begin with, note that the fact that people agree on the favored intuitions does not mean that there is any positive reason to think that they are reliably formed. It just means that one reason to doubt their reliability is absent. The agreement provides a positive reason only if the assumption that the intuitions are reliable obtains support from the best account of why the agreement obtains, and there are obviously lots of possible explanations that are not vindicating in this sense.

Second, and more importantly, the resulting set is probably going to be quite limited, which makes it likely that its elements will radically underdetermine theory choice in ethics. After all, the fact that 'betterness' is transitive is not going to help us adjudicate between, say, Kantianism, utilitarianism and virtue theory. This is presumably why the debate between the advocates of these theories is as live today as it has ever been, in spite of the fact that all participants implicitly practice the method of appealing to intuitions that is the focus of this paper. Accordingly, the unthreatened status of the intuitions that are shared will not allow us to avoid the skeptical conclusion Stich et al seek regarding claims beyond those rather vacuous views that are included in that set.

Third, the set may have to be narrowed down even further. The reason is that some of the moral intuitions that are more or less universally shared appear to be inconsistent with each

\footnotetext{
${ }^{14}$ It might also be held that the extent of intuitional disagreement is exaggerated since the evidence is based on people's verbal responses to certain simple narratives that are open to multiple interpretations. Thus, one may question if those responses always do manifest views that genuinely conflict with ours. This possibility is mentioned in Nichols' and Ulatowski's 'Intuitions and Individual Differences: The Knobe Effect Revisited'. It is adduced in defense of intuitions by Sosa in his 'Experimental Philosophy and Philosophical Intuition'.
} 
other, as for example the contemporary discussion in population ethics illustrates. This is why Parfit is able to generate his 'mere addition paradox' and why the search for the Theory $\mathrm{X}$ that is aimed at given satisfactory answers to issues regarding future generations has turned out to be so elusive. ${ }^{15}$ Any statement can be derived from an inconsistent set. So if the claims that are supposed to comprise our basic evidence in ethics form such a set, they give us little reason to trust the conclusions we can derive from it. In such a case, our evidence would be ambiguous in the sense that it would provide equal support for all theories (i.e., none at all). And that is just another way of formulating the skeptical conclusion that Stich et al seek.

To avoid that conclusion, we need to revise the inconsistent set by dropping some of its members. Which ones? Since none of the intuitions is contested, we must point to some other factor that suggests that it is not trustworthy. Moreover, the explanation we thus come up with must be consistent with continued confidence in the other intuitions of the set. That is, it must leave the ground for the assumption that the others are reliably formed intact.

A similar point pertains to the worry that the set of intuitions that are untouched by arguments from disagreement is, even assuming that it is not inconsistent, so limited that it radically underdetermines theory choice. We can try to expand the set of 'favored' intuitions by including also those that are only contested by persons who we have some independent reason to think are in some way incompetent. Such a reason would consist in some consideration suggesting that their verdicts are influenced by factors that we have independent reason to think sap their reliability. And, again, such an attempt to explain away the recalcitrant verdict must be consistent with the assumption that there are other 'intuiters' (such as us) whose reliability is not sapped in this way.

An explanation that violates this condition is offered by John Broome. Broome favors a version of consequentialism. He also concedes that 'ethics must ultimately be founded on some sort of intuition'. ${ }^{16}$ However, there are intuitions with which his theory conflicts. For example, it implies 'the repugnant conclusion'; i.e., the view that, in Parfit's well-known example, the Z-world, in which enormous numbers of people live lives that are barely worth living, is better than the A-world, in which ten billion people live lives with a very high quality of life. As the name suggests, a lot of people intuit that this conclusion is incorrect, and Broome acknowledges the need to explain away that fact. He tries to do so by stressing

\footnotetext{
${ }^{15}$ See Parfit's discussion in the fourth part of Reasons and Persons (Oxford: Clarendon, 1984). The inconsistency is strictly proven by Gustaf Arrhenius in his Population Ethics, Oxford: Oxford University Press, forthcoming in 2012.

${ }^{16}$ Weighing Lives, 212.
} 
that we have no reason to 'rely on our intuitions outside the domain where we have grounds for thinking they are reliable' and by suggesting that the intuition about the repugnant conclusion is outside of that domain. ${ }^{17}$ The reason is supposed to be that it is 'about very large numbers'. According to Broome, '[e]ven the best philosophers cannot get an intuitive grasp of, say, tens of billions of people. ${ }^{18}$ This is supposed to justify him in holding on to his theory even if it conflicts with the intuition about the repugnant conclusion.

What Broome suggests, in effect, is that there are areas where we do have grounds for thinking that our intuitions are reliable. In what do those grounds consist? Broome appeals to the idea that 'our moral intuitions are formed and polished in our homely interactions with the few people we have to deal with in ordinary life'. ${ }^{19}$ It is this 'polishing', it appears, that is supposed to be the source of reliability of the intuitions he thinks we can trust and that is crucially absent in the case of the intuition about the repugnant conclusion.

What Broome seems to have in mind by the talk of our intuitions being 'polished' is a method for exploring the reliability of a source of evidence known as 'calibration' ${ }^{20}$ For example, consider telescopes. The reliability of a telescope could be established by pointing it at some object whose properties (shape, color, etc) can be ascertained through independent means. If there are deviances, perhaps under certain circumstances, then we could try to adjust the instrument, or ignore the verdicts it gives under those circumstances. However, as we have no useful experiences of dealings with billions of people, we haven't received the kind of feedback that has allowed us to calibrate our intuitions about such cases.

This attempt to explain away the intuition about the repugnant conclusion violates the condition mentioned earlier, since it does not leave the ground for considering the others to be reliable intact. The reason is that no moral intuitions are calibrated in the relevant sense, for the obvious reason that there is no independent way of checking their truth. What we can do, perhaps, is to compare our intuitions with our ethical theories or other ethical beliefs. But since we have assumed (by ignoring the objection to the relevance of RIT mentioned in section 3) that intuitions exhaust the evidence we may have for these theories, this means, in effect, that we merely compare some intuitions with others. And that does not represent a way

\footnotetext{
${ }^{17}$ Weighing Lives, 56.

${ }^{18}$ Weighing Lives, $56 \mathrm{f}$.

${ }^{19}$ Weighing Lives, 56.

${ }^{20}$ For this notion and its relevance in the present context, see Cummins, R., 'Reflection on Reflective Equilibrium,' in DePaul, M. and Ramsey, W. (eds.), Rethinking Intuition: The Psychology of Intuition and its Role in Philosophical Inquiry. Rowman and Littlefield, 1998, 113-128.
} 
of checking them independently. ${ }^{21}$ Thus, by arguing that some intuitions are not reliable on the ground that our capacity to make them is not calibrated, one commits oneself to a skeptical attitude towards intuitions in general.

To explain away a recalcitrant verdict in the required way is to attribute it to a factor that can plausibly be seen to sap an otherwise reliable process. Whether a factor can plausibly be seen in this way depends presumably on why the process is supposed to be reliable. The explanation should therefore take its point of departure in a believable answer to that question. Giving such an account amounts to developing a positive defense of the reliance on intuitions. In my view, the requirement to provide such an account, given the negative bits of evidence empirical research has revealed, is the real source of skeptical worries. Notice in this context that there is such a positive defense in the case of observations. What we know about how they are formed does deliver a positive verdict about their reliability. This is the account I alluded to earlier, which involves assumptions about the nature of the sense organs, about how they have evolved and interact with our environments, etc. The existence of that account is epistemically significant, even if it is also the case that there is less negative evidence against their reliability, in the form of worrying sensitivities of the kind the empirical studies suggest obtain in the case of moral intuitions.

\section{Theory-dependent justifications}

The upshot of the discussion in the previous paragraph is that the data Stich et al appeal are worrying ultimately because they raise the need to provide a defense of the reliance of intuitions in the form of a believable account of their origins that generates a positive verdict about their reliability. I shall now turn to a proposal about how to meet that requirement. What is characteristic about it is that it invokes substantive moral assumptions. I shall call such attempts to justify the reliance on intuitions 'theory-dependent'.

How could the invocation of moral assumptions help? The point of departure of the strategy is the observation that at least some of the empirical results to which the skeptics appeal do not generate any skeptical conclusions by themselves. The results in question are supposed to lead to skepticism on the ground that they suggest that our intuitions are the

\footnotetext{
${ }^{21}$ This is something Broome himself seems willing to concede: 'If an engineer gets her calculations wrong, her mistake will be revealed when the bridge falls down. But a mistake in moral theory is never revealed like that. If we do something wrong, we do not later see the error made manifest.' (Weighing Lives, 57) Of course, we get some kind of feedback also in the moral case. If we make a moral judgment and act on it, people in our environment, might react and try to make us see the (alleged) light. This might help bringing our intuitions in line with those of our peers. But where that leaves their reliability is another question.
} 
results of factors that vary independently of their truth. However, notice that the second bit of that claim-the claim that the pertinent factors vary independently of the truth of the intuitions - is a moral claim. For example, suppose that it is found that we intuitively judge an action to be right depending on if the action in question has some non-moral feature $\mathrm{F}$ that triggers a certain emotional response. Whether this undermines the view that if we intuit that an action is right this indicates that it is right (and thus that the intuition is true) depends on how $\mathrm{F}$ is related to moral rightness. And that's a moral question.

Some defenders of the reliance on intuitions, such as David Copp, have taken this to mean that something fishy is going on with the challenge. ${ }^{22}$ Indeed, Copp suggests that the fact that it implicitly relies on moral assumptions suggests that it is incoherent. For what reasons could we possibly have for accepting those implicit assumptions? Surely, we must consult our intuitions. Thus, the challenge seems to presuppose the very thesis that it is aimed at refuting, namely that intuitions deserve being treated as evidence. In other words, advocates of the challenge seem committed to thinking that at least some moral intuitions can serve as premises in respectable philosophical arguments.

But this objection is unconvincing. For the challenge can be construed as a reductio. The skeptical arguments that rely on the findings about the factors that influence our intuitions presuppose that those factors are not morally relevant. An advocate of the argument could begin by pointing out that our intuitions in fact support those assumptions. So, if we suppose that our intuitions are reliable, we should embrace them. But then, we are, via the empirical findings, led to conclude that our intuitions are not reliably formed, which is contrary to our initial supposition. Clearly, to make this point, one neither has to commit to that supposition nor to the intuitions needed to bring out the conflict.

However, the basic point - the claim that the pertinent empirical results don't lead to any skeptical conclusions by themselves but only in conjunction with moral assumptionsremains sound. One way of resisting specific versions of the challenge is accordingly to reject the moral assumptions on which they implicitly rely. To see how this works, it is helpful to take a closer look at such a version. I shall focus on the much-discussed argument against moral realism that has been offered by Sharon Street. ${ }^{23}$

\section{Evolution and reliability}

\footnotetext{
${ }^{22}$ In 'Experiments, Intuitions, and Methodology in Moral and Political Theory', forthcoming.

${ }^{23}$ In the paper 'A Darwinian Dilemma for Realist Theories of Value', Philosophical Studies 127, 2006, 109-166. The argument is slightly adapted to suit the present purpose.
} 
Street's point of departure is an evolutionary account of our moral intuitions, according to which they are, in part, the result of tendencies that have evolved through natural selection (because the possession of them enhances our fitness, or enhanced the fitness of our ancestors). The argument is aimed to show that, given such an account, realists are committed to a form of skepticism, which in turn is held to undermine their position.

Street begins by noting that a realist may have different beliefs about the relation that holds between the Darwinian forces that, we assume, have shaped our intuitions and the moral facts that the realist posits. The realist could either hold that there is a relation-in the sense that if the moral facts had been different then the Darwinian forces would have caused us to have different moral intuitions - or deny that there is a relation. I shall call the latter option 'the no-relation assumption'.

According to Street, if a realist chooses the first option and insists that there is a relation then she commits herself to something she calls 'the tracking account'. The evolutionary approach entails that we are disposed to have certain moral intuitions because having that disposition gave our ancestors a selective advantage. According to the tracking account, they gave them that advantage because the intuitions in question are often true.

The problem with the tracking account, according to Street, is that there is a superior competitor, namely what she calls 'the adaptive link account'. According to the adaptive link account, the selective advantage provided by our intuitions is to be explained in terms of features of the behavior they give rise to rather in terms of their truth. For example, why are we disposed to intuit that it is bad to be a free-rider? Roughly, according to the adaptive link account, because the possession of that intuition prompted our ancestors to avoid free-riding, which in turn helped them to avoid many damaging collective dilemmas. Unlike the tracking account, this version is neutral towards moral issues and does not posit any moral truths.

Street thinks that the adaptive link account can be shown to be superior to the tracking account on purely scientific grounds, for example because it is simpler (in that it doesn't posit any moral facts). A realist should therefore reject the tracking account. But, according to Street, if she rejects the tracking account then she is committed to the no-relation assumption and must concede that the forces of natural selection have pushed our moral intuitions in a certain direction independently of whether the truth lies in that direction. If so, and if the contents of our intuitions have indeed been shaped by Darwinian forces, then whether they are true or not is a matter of pure chance. And chance is not a reassuring source of justification, neither for the intuitions themselves nor for the further beliefs that we are disposed to form on the basis of them. Thus, either way-regardless of what view a realist 
takes on the no-relation assumption - she is forced to accept a problematic conclusion. If she insists that there is a relation, then she is committed to the implausible tracking account. If she denies a relation, she is instead committed to a form of skepticism.

This is a version of the challenge that provides the focus of my paper, as the point is that an evolutionary account of our moral intuitions undermines the idea that we have reason to trust the propositions that constitute their contents on the ground that they are intuitively held. And as other versions, it relies on moral assumptions. Street assumes that, by embracing the adaptive link account, a realist commits herself to the no-relation assumption. However, note that the adaptive link account cannot establish the no-relation assumption by itself. Street seems to think that if one concedes that we intuitively judge, say, that it is right to $\phi$ because $\phi$ :ing increases the agent's fitness then one must conclude that we would have had that intuition even if $\phi$ had not been right, since $\phi$ :ing would still have been fitness-enhancing. But that depends on how fittingness and rightness are related. And, on some moral views, it doesn't hold.

The simplest way to see this is to consider a view that may be given the name 'fitnessism'. According to fitnessism, an act is right if and only if it enhances the agent's fitness. On this view, if it had not been right to $\phi$ then $\phi$ would not have enhanced fitness. So, if $\phi$ had not been right, we would not, given the adaptive link account, have intuited that it is right. Thus, given fitnessism, one can accept the adaptive link account and still reject the norelation assumption. Hence, given fitnessism, the adaptive link account doesn't undermine the thought that the propositions that constitute the contents of our intuitions deserve being trusted because they are intuitively held.

Of course, if a response of the type I want to explore commits us to a position such as fitnessism, it is not of much help, given the absurdity of that position. A major problem is that it conflicts with our intuitions. After all, it is easy to imagine cases in which an action would enhance the agent's fitness and still be morally objectionable. This makes the defense selfdefeating. For if it is successful, and justifies the reliance on intuitions, then it is flawed, as those intuitions refute one of its essential elements (namely fitnessism).

However, as for example David Enoch has noted, we can achieve similar results by using less contentious moral background assumptions. Note that, to avoid strong forms of skepticism, it is enough if there is a probabilistic dependency between the existence of our intuitions and their truth. That is, a skeptic has to show that the fact that we intuit that, say, an action is right doesn't even increase the likelihood of it being right (or of the intuition being true). And Enoch's point is that, given certain initially plausible moral views, the adaptive 
link account does not support such a conclusion. On the adaptive link account, roughly, we intuit that actions are right to the extent that they increase the agent's fitness, and the actions have that propensity, in many cases, through promoting the agent's survival. Now, consider the thesis that survival is something good. Since the fact that actions promote something good contributes to making it right, the thesis that survival is good supports thinking that the fact that an action increases the agent's fitness indicates that it is right. Thus, given the thesis in question, the adaptive link account can, after all, be reconciled with the view that if we intuit that an action is right this indicates that the action is right and that the intuition is true. And the crucial point is that the auxiliary assumption used in this case (the thesis that survival is something good) does not, unlike fitnessism, seem to conflict radically with our intuitions. ${ }^{24}$

\section{A vicious circle?}

Let us say that if an account of the origins of our intuitions supports RIT (i.e., the conclusion that the fact that a moral proposition is intuitively held is (at least in some cases) evidence that it is true) then it is vindicating. The idea underlying theory-dependent attempts to justify the reliance on intuitions is to construct such an account by combining empirical claims about the origins of our intuitions with moral assumptions such that, given those assumptions, the empirical claims imply that the intuitions are appropriately sensitive to their truth.

An obvious objection to the theory-dependent approach is that it involves a kind of circularity. For, again, how are we to establish the auxiliary moral assumptions? If we exclude the possibility that moral claims can be justified with reference to items from other sources of evidence, such as observations, we have to consult our intuitions. Thus, the account justifies the reliance on intuitions only given the prior assumption that they are indeed reliable.

However-and this is the crucial point-that's an objection a skeptic can't use. For remember that skeptics try to establish a contrast between intuitions and observational beliefs. That is, they try to show that intuitions don't deserve being treated as evidence on the assumption that observational beliefs do. And the justificatory account that is available in the observational case also involves a kind of circularity. It consists of empirical claims about how our sense organs have evolved, and so on. And what reasons could we possibly have for

\footnotetext{
${ }^{24}$ See Enoch's 'The epistemological challenge to metanormative realism: how best to understand it, and how to cope with it', Philosophical Studies 148, 2010, 413-438, esp. pp. 430-5. Similar suggestions are made by others, although the moral background assumptions employed are different. See Brosnan, K., 'Do the evolutionary origins of our moral beliefs undermine moral knowledge?', Biology and Philosophy 26, 2011, 5164, Schafer, K., 'Evolution and Normative Scepticism', Australasian Journal of Philosophy 88, 2010, 471-488, and Skarsaune, K., 'Darwin and Moral Realism: Survival of the Iffiest', Philosophical Studies 152, 2011, 229243.
} 
accepting those claims, besides those that are provided by observations? As I mentioned in the beginning of the paper, there is arguably no source of evidence that can be justified in an entirely independent and non-circular way. Defenders of the reliance on intuitions insist sometimes that if one is a skeptic about intuitions then one commits oneself to global skepticism. ${ }^{25}$ Using the circularity-objection makes a skeptic vulnerable to that charge.

In other words, if it is legitimate to proceed from an initial presumption in favor of the reliability of observational beliefs in trying to establish that they are reliable, making a similar presumption in favor of intuitions is presumably equally legitimate. So, if we want to dismiss attempts to defend the reliance on intuitions by providing a theory-dependent justification of them, then the fact that it involves circularity cannot be our only complaint. That is, we must appeal to other problems with the attempted defense besides the circularity. ${ }^{26}$

\section{Some conditions}

The main point I want to make is that there are such problems, and that instances of the theory-dependent defense need not be successful just because their circularity doesn't defeat them. I shall try to bring this out by stating a set of conditions that a satisfactory theorydependent justification arguably must satisfy. By 'the target intuitions' I refer to the intuitions whose reliability is to be established. In what follows, recall that a positive account of the reliability of intuitions of the kind that will be discussed here constitutes of two components: A set $\mathbf{E}$ of empirical assumptions about the origins of the target intuitions and a set $\mathbf{M}$ of moral claims such that the thesis that they are reliably formed can be derived from the conjunction of $\mathbf{E}$ and $\mathbf{M}$. The source of inspiration of the conditions I shall state is provided by certain features of the justificatory story that are available in the case of perceptual beliefs.

First, the justificatory story available in the observational case involves circularity, because observations have to be invoked to establish the empirical claims it involves (such as the claims about how our sense organs have evolved). But it is important to realize that our observations actually do support and confirm those claims and that, although circularity is involved, the fact that this fit obtains represents a real achievement. ${ }^{27}$ The initial presumption

\footnotetext{
${ }^{25}$ This type of argument is pursued for example in Pust, J., Intuitions as Evidence. New York and London: Garland Publishing, 2000.

${ }^{26}$ This is related to the earlier mentioned fact that intuitions and observations are in the same boat as far as the possibility of calibration is concerned. There is no independent way of ascertaining the truth of observational beliefs (independent of treating observations as evidence).

${ }^{27}$ See further Shogenji, T., 'Self-Dependent Justification Without Circularity', British Journal for the Philosophy of Science 51, 2000, 287-298.
} 
in favor of the reliability of perceptual beliefs could conceivably have led to a more negative verdict about their reliability. A similar fit or coherence should be achieved by an account of the reliability of moral intuitions. That is, the target judgments must confirm, or at least not conflict with, the moral assumptions that it invokes. For if it doesn't, then the story is selfdefeating in the way I described in connection with the above remarks about fitnessism. The condition can be stated as follows.

COHERENCE: The target intuitions support (do not conflict with) the members of $\mathbf{M}$.

Second, note that the claims invoked by the justificatory account that is available in the perceptual case are neutral relative to many of the issues we try to answer by consulting our perceptual beliefs. The assumptions concern the nature of our sense organs, and so on, and have little relevance to many other of the issues that are addressed for example in the sciences. This means that we may accept the assumptions invoked by the justificatory account and still think that consulting our perceptual beliefs is indispensable in our cognitive endeavors. If we want to show that observational beliefs and moral intuitions are on a par, then our account of the reliability of the latter must satisfy a similar condition. After all, if we, by helping ourselves to the assumptions we need to make an empirical account of our intuitions vindicating, can answer all the moral questions we face without consulting our intuitions, not much is achieved. Suppose that the moral propositions whose truth-values we want to determine by consulting our intuitions form the set $\mathrm{S}$. The condition is:

NEUTRALITY: There are members of S such that neither their truth nor their falsity can be derived from $\mathbf{M}$, not even when $\mathbf{M}$ is combined with relevant empirical assumptions.

Third, we should require that the conclusion we gain support for is sufficiently strong. The justificatory story pertinent to observational beliefs supports thinking that, in many cases, the truth of the proposition that constitutes the content of an observation is entailed by the best explanation of it. That is, it supports the view that, normally, when we observe that something is, say, red, this is best explained by assuming that it is red. We may not be able to obtain a similar result in the case of moral intuitions, and, given for example the account of the reliability of our intuition that invokes fitnessism, we don't. For it is assumed that the evolutionary account explains our intuitions by itself, without having to invoke fitnessism. But, as that example also illustrates, such an account may still support the conclusion that the 
fact that we intuit that $\mathrm{P}$ strongly suggest that $\mathrm{P}$, since this conclusion can be derived from the conjunction of fitnessism and the evolutionary account. The present suggestion is in any case that the support must be strong enough. I shall call this vague condition RELIABILITY:

RELIABILITY: For each of the target intuitions, the conjunction of $\mathbf{M}$ and $\mathbf{E}$ entails that the fact that the proposition that constitutes its content is intuitively held strongly supports that it is true.

\section{Reliability, coherence and neutrality}

Are there any instances of the theory-dependent approach that satisfy all three conditions? That's the crucial question. In my view, the prospects for an affirmative answer are not good. For example, RELIABILITY is clearly satisfied by the position that combines an evolutionary account with fitnessism. The evolutionary account suggests that the actions we intuitively judge to be right are fitness-enhancing, at least in certain conditions, and fitnessism entails that if an act enhances the agent's fitness then it is right. However, as I have already indicated, since we can easily imagine situations in which actions we intuitively think are wrong enhance the agent's fitness, it hardly satisfies COHERENCE.

It also violates NEUTRALITY. For, if we can help ourselves to fitnessism, we can simply deduce the answers to every issue about rightness that we confront, given the empirical facts at hand. No intuitions have to be involved. Incidentally, NEUTRALITY is also violated by attempts to respond to the skeptics' challenge according to which moral facts can be reduced to naturalistic facts that can be detected empirically, which is a strategy sometimes pursued by realistically inclined philosophers. ${ }^{28}$

As for the idea of combining an evolutionary account with the weaker moral background assumptions hinted at by Enoch, there are other problems. For example, consider RELIABILITY. If the evolutionary account is correct then which actions we intuitively judge to be right is sensitive to whether the actions being evaluated promote the agent's survival and, perhaps, the survival of her kin. So we may perhaps infer from the fact that an action is intuitively judged to be right that it promotes the agent's survival. But if the idea that survival is good is interpreted as stating that it is good somehow in general then that fact provides very limited support for the truth of the intuition. For it may of course be detrimental to the

${ }^{28}$ This option is pursued by David Copp in 'Darwinian Skepticism about Moral Realism', Philosophical Issues 18, 2008, 186-206, see esp. 198-204. 
survival of others. So, the account does not satisfy RELIABILITY to any significant extent. If we on the other hand take the idea that survival is good to mean only that agents have a reason to promote their own survival then it is, again, doubtful that it satisfies COHERENCE. This means that, if we don't want to violate COHERENCE; what we at best get out from this proposal, in terms of reliability, is something very modest.

There is a further reason to be skeptical about Enoch's proposal. It has to do with the fact that one point of developing a justificatory story is to provide resources for explaining away dissenting verdicts on judgments one intuits to be correct in a way that allows one to have continued trust in one's own verdicts. Note that disagreements occur also, occasionally, regarding perceptual matters, and that the story available there does provide resources for such explanations. Those disagreements can normally be attributed to sub-optimal perceptual conditions, such as bad lighting, and that such conditions sap an observer's reliability is what we are led to expect by the account of how our sense organs work, and so on. That is, it explains why perceptual beliefs formed under the conditions described as 'sub-optimal' are not reliable, while still supporting the view that perceptual beliefs formed under other, normal conditions are. A successful defense of moral intuitions should have the same feature. It should explain why the absence of the influence of the factors we need to invoke in order to discard dissenting intuitive verdicts promotes reliability.

Now, Enoch's proposal offers very little help in that context, since the support it provides to our intuitions is so indiscriminate. If our intuitions are the result of tendencies that have evolved through natural selection, then, presumably, all types of actions that they prescribe promote survival. This means that Enoch's proposal does not help us to extend the set of intuitions to which we can plausibly appeal beyond those that are universally shared, which in turn means that the intuitions it favors underdetermine (and thus cannot confirm) the moral assumptions invoked by the account (even if the assumptions themselves, in virtue of their weakness, have an intuitive appeal). Thus, the fact that the account fails to provide help regarding how to explain about intuitions dissent generates a difficulty regarding COHERENCE. So, at least in the case of the instances of the theory-dependent approach that have been considered in this paper, they fail to satisfy the relevant conditions.

\section{Conclusion}

Of course, the instances I have considered do not exhaust the options. There may be others that are more promising. But what the above discussion illustrates, it seems to me, is that COHERENCE, NEUTRALITY and RELIABILITY interact in an unhappy way. For the 
stronger moral background assumptions we invoke (stronger in the sense that they allow us to conclude that the fact that we have certain moral intuitions strongly suggest that they are true) the worse the resulting account fares when it comes to NEUTRALITY. On the other hand, the weaker assumptions we invoke, the worse it fares relative to RELIABILITY. The upshot is that no theory-dependent defense of the reliability of moral intuitions is likely to be successful. Or, differently put, any such defense seems likely to work (such that it satisfies COHERENCE and RELIABILITY) only if it is not really needed (violates NEUTRALITY)!

There is tension also if one merely focuses on COHERENCE and RELIABILITY. The general moral views we have the greatest hope of being able to justify with reference to the intuitions whose reliability we in turn have the greatest hope of defending are presumably those that are the serious contenders in the current debate, including utilitarianism, Kantianism and virtue theory. However, it is doubtful if any of those theories generates the conclusion that the fact that we have the target intuitions strongly suggests that they are true, at least when combined with an evolutionary account of the sort I have focused on. For example, consider the utilitarian view that an act is right if and only if it maximizes the total net sum of welfare. Given an evolutionary account, the fact that we intuit that an action is right suggests perhaps that it is fitness-enhancing. But the question is whether it also suggests that the action is right (and that the intuition is correct). And, given utilitarianism, that seems unlikely. After all, clearly, an action can promote the agent's fitness and have catastrophic consequences concerning the welfare of others. If I am right that a similar conclusion holds for the other serious contenders, and that they are the ones most likely to be justifiable with reference to the target intuition, then no account that satisfies RELIABILITY is also likely to meet COHERENCE, at least given an evolutionary approach. Gilbert Harman has famously said that the problem with ethics is that ethical theories are immune to observational testing. ${ }^{29}$ On the basis of the tension between RELIABILITY and COHERENCE, I am inclined to think that the basic problem is rather that ethics is not even self-confirmatory. ${ }^{30}$

\section{References}

Arrhenius, G., Population Ethics, Oxford: Oxford University Press, forthcoming in 2012.

\footnotetext{
${ }^{29}$ The Nature of Morality, New York: Oxford University Press, vii-viii.

${ }^{30}$ It might be objected to this reasoning that the evolutionary account to which I have kept returning is quite controversial, and that there is no sufficiently precise version of it that has actually been established scientifically. In fact, it might be stressed, we still know little about the origins of our intuitions. That is true, but it provides little comfort for a non-skeptic. Instead, it provides further reason to think that, presently at least, we have no well-established and satisfactory positive account of the alleged reliability of our moral intuitions.
} 
Broome, J., Weighing Lives, Oxford: Oxford University Press, 2004.

Brosnan, K., 'Do the evolutionary origins of our moral beliefs undermine moral knowledge?', Biology and Philosophy 26, 2011, 51-64.

Copp, D., 'Darwinian Skepticism about Moral Realism', Philosophical Issues 18, 2008, 186206.

Copp, D., 'Experiments, Intuitions, and Methodology in Moral and Political Theory', forthcoming.

Cummins, R., 'Reflection on Reflective Equilibrium,' in DePaul, M. and Ramsey, W. (eds.), Rethinking Intuition: The Psychology of Intuition and its Role in Philosophical Inquiry. Rowman and Littlefield, 1998, 113-128.

Enoch, D., 'The epistemological challenge to metanormative realism: how best to understand it, and how to cope with it', Philosophical Studies 148, 2010, 413-438.

Goldman, A., and Pust, J., 'Philosophical theory and intuitional psycho-evidence', in DePaul, $\mathrm{M}$ and Ramsey, W., (eds.), Rethinking Intuition: The Psychology of Intuition and its Role in Philosophical Inquiry, Maryland: Rowman and Littlefield, 1998, 179-200.

Harman, G., 'Moral Relativism Defended', Philosophical Review 84, 1975, 3-22.

Harman, G., The Nature of Morality, New York: Oxford University Press, 1977.

Huemer, M., Ethical Intuitionism, Palgrave Macmillan, 2006

Kornblith, H., 'Naturalism and Intuitions', Grazer Philosophische Studien 74, 2007, 27-49.

Liao, M., 'A Defense of Intuitions.' Philosophical Studies 140, 2008, 247-262.

Nichols, S., Stich, S., and Weinberg, J., 'Metaskepticism: Meditations in EthnoEpistemology', in Luper S., (ed.), The Skeptics, Burlington, VT: Ashgate, 2003.

Nichols, S., and Ulatowski, J., 'Intuitions and Individual Differences: The Knobe Effect Revisited'. Mind \& Language 22, 2007, 346-365.

Parfit, D., Reasons and Persons, Oxford: Clarendon, 1984.

Pust, J., Intuitions as Evidence. New York and London: Garland Publishing, 2000.

Schafer, K., 'Evolution and Normative Scepticism', Australasian Journal of Philosophy 88, 2010, 471-488.

Shogenji, T., 'Self-Dependent Justification Without Circularity', British Journal for the Philosophy of Science 51, 2000, 287-298.

Skarsaune, K. O., 'Darwin and Moral Realism: Survival of the Iffiest', Philosophical Studies 152, 2011, 229-243.

Sosa, E., 'Experimental Philosophy and Philosophical Intuition', Philosophical Studies 132, 2007, 99-107.

Stich, S., 'Reflective Equilibrium, Analytic Epistemology and the Problem of Cognitive Diversity', in DePaul, M. and Ramsey, W. (eds.), Rethinking Intuition: The Psychology of Intuition and its Role in Philosophical Inquiry, Maryland: Rowman and Littlefield, 1998, 95-112.

Stich, S., 'Replies', in Murphy, D., (ed.), Stich and his critics, Melden, MA: Blackwell, 2009, 190-252.

Street, S., 'A Darwinian Dilemma for Realist Theories of Value', Philosophical Studies 127, 2006, 109-166.

Swain, S., Alexander, J. and Weinberg, J., 'The instability of philosophical intuitions:

Running hot and cold on Truetemp'. Philosophy and Phenomenological Research 76, 2008, 138-155.

Tersman, F., Reflective Equilibrium, Stockholm: Almqvist \& Wiksell, 1993.

Tersman, F., Moral Disagreement, New York: Cambridge University Press, 2006.

Tersman. F., 'The Reliability of Moral Intuitions: A Challenge from Neuroscience', Australasian Journal of Philosophy86, 2008, 389-405.

Thomson, J., 'Killing, Letting Die, and the Trolley Problem', The Monist 59, 1967, 204-217. 
Weinberg, J., 'How To Challenge Intuitions Empirically Without Risking Skepticism', Midwest Studies in Philosophy: Philosophy \& the Empirical 31, 2007, 318-343.

Williamson, T., The Philosophy of Philosophy, Oxford: Blackwell, 2008.

Williamson, T., 'Replies to Ichikawa, Martin and Weinberg', Philosophical Studies, 2009. Wong, D., Moral Relativity. Berkeley: University of California Press, 1984. 